\title{
A REPERCUSSÃO GERAL NO RECURSO EXTRAORDINÁRIO 654.833/AC E O RISCO DA PRESCRIÇÃO DO DANO AMBIENTAL
}

\author{
José Valente Neto* \\ Jânio Pereira da Cunha**
}

\section{Resumo:}

O artigo analisa o dano ambiental e a repercussão geral no Recurso Extraordinário 654.833/AC, que envolve a tese da prescrição do dano ambiental. A importância do assunto reside nos impactos do progresso tecnológico no meio ambiente e nas gerações futuras dos seres vivos. O método de pesquisa consistiu na leitura de livros e de artigos. Além disso, examinaram-se decisões judiciais dos Tribunais Superiores. Verificou-se, em conclusão, que os reflexos da degradação ambiental são significativos em países em desenvolvimento, como o Brasil, e que a tese da prescrição do dano ambiental representará um retrocesso sem precedentes.

Palavras-chave: Dano; Meio Ambiente; Responsabilidade civil; Risco; Prescrição

\section{GENERAL REPERCUSSION IN EXTRAORDINARY APPEAL 654.833/AC AND THE RISK OF PRESCRIPTION OF ENVIRONMENTAL DAMAGE}

\begin{abstract}
:
The article analyzes the environmental damage and the general repercussion in Extraordinary Appeal 654.833/AC, which involves the thesis of the prescription of environmental damage. The importance of the subject lies in the impacts of technological progress on the environment and future generations of living beings. The research method consisted of reading books and articles. In addition, judicial decisions of the Superior Courts were examined. In conclusion, it was found that the effects of environmental degradation are significant in developing countries, such as Brazil, and that the thesis of the prescription of environmental damage will represent an unprecedented setback.
\end{abstract}

Keywords: Damage; Environment; Civil Responsability; Risk; Prescription

\section{INTRODUÇÃO}

Há três décadas, a Constituição Federal ${ }^{1}$ representou um marco na defesa do meio ambiente. No século XXI, a expansão do agronegócio e o seu prestígio na balança comercial

\footnotetext{
* Doutorando em Direito (UFC). Mestre em Direito Constitucional (UNIFOR). Defensor Público do Estado do Ceará. Email: josevalenteneto1979@gmail.com.

** Professor do Curso de Direito e do Programa de Pós-Graduação em Direito (Mestrado) do Centro Universitário Christus (UNICHRISTUS). Professor do Curso de Direito da Universidade de Fortaleza (UNIFOR). Doutor em Direito Constitucional (UNIFOR). Email: janiopcunha@ hotmail.com.
} 
põem em xeque a consecução dos princípios e regras constitucionais. Assim, o artigo analisa a proteção e os desafios ao meio ambiente no Brasil e, especificamente, almeja-se obter respostas a quatro perguntas: i) quais são os reflexos do (sub)desenvolvimento econômico no meio ambiente; ii) qual o nível de efetividade da tutela jurídica?; iii) quais os principais obstáculos à preservação ambiental?; e (iv) a prescrição do dano ambiental representará retrocesso na proteção do meio ambiente?

A relevância do tema reside na advertência da maioria dos cientistas sobre os impactos significativos do progresso tecnológico nos ecossistemas e suas repercussões transfronteiriças. A questão deixou de se circunscrever ao círculo de ativistas e passou a ser pauta obrigatória nas agendas dos Estados, organizações internacionais e de vários segmentos da sociedade. Se, antes, havia uma preponderância de pesquisadores das ciências exatas, hoje percebe-se um equilíbrio na comunidade científica e, em especial, um recrudescimento de estudos no âmbito do direito, sobretudo após a Constituição do Equador de 2008, a qual, de forma pioneira, contemplou a natureza como sujeito de direitos ${ }^{2}$.

$\mathrm{O}$ artigo divide-se em três seções. Na primeira, a partir da análise do capitalismo, realiza-se uma provocação sobre um enigmático século XXII. Em sequência, procura-se estabelecer um conceito de dano ambiental. Além da definição, faz-se um esboço sobre a evolução da proteção do meio ambiente no Brasil. No último tópico, exploram-se as seguintes questões materiais e processuais da disciplina jurídica do dano ambiental: i) a natureza da responsabilidade civil por dano ambiental: a teoria do risco integral e a solidariedade; ii) o devido processo ambiental: denunciação da lide, inversão do ônus da prova e desconsideração da personalidade jurídica; e iii) a tese da (im)prescritibilidade do dano ambiental, objeto da Repercussão Geral no Recurso Extraordinário 654.833/AC. O método de pesquisa empregado foi o bibliográfico e o exame da jurisprudência dos Tribunais Superiores, principalmente do Superior Tribunal de Justiça.

\footnotetext{
1 “Art. 225, caput. Todos têm direito ao meio ambiente ecologicamente equilibrado, bem de uso comum do povo e essencial à sadia qualidade de vida, impondo-se ao poder público e à coletividade o dever de defendê-lo e preservá-lo para as presentes e futuras gerações”. CONSTITUIÇÕES DO BRASIL, 2000, p. 102.

2 "Art. 71. La naturaleza o Pacha Mama, donde se reproduce y realiza lavida, tienederecho a que se respete integralmente suexistencia y elmantenimiento y regeneración de sus ciclos vitales, estructura, funcionesy procesos evolutivos.Toda persona, comunidad, pueblo o nacionalidadpodrá exigir a laautoridad publicaelcumplimiento de losderechos de lanaturaleza. Paraaplicar e interpretar estosderechos se observaranlosprincípios establecidos em laConstitución, enlo que proceda.El Estado incentivará a las personas naturales y jurídicas, y a loscolectivos, para que protejanlanaturaleza, y promoverá elrespeto a todoslos elementos que formanunecosistema".CONSTITUCIÓN DELA REPÚBLICA DEL ECUADOR. STF, 2008, online.
} 


\section{SÉCULO XXII?}

A sofisticação do sistema capitalista transformou-se em uma incógnita: há certeza sobre o futuro do meio ambiente? Os sociólogos e os antropólogos sempre tiveram como premissa de suas teses o vínculo direto entre as questões econômicas e não econômicas na maior parte das sociedades do Ocidente. O domínio extraeconômico passou a ser delimitado pelo econômico em quase todos os sentidos, do jurídico ao político.Com efeito, deve-se sempre ponderar o fato de "os fenômenos sociais e culturais não estarem a 'reboque', seguindo os fenômenos econômicos a distância: eles estão, em seu surgimento, presos na mesma rede de relações" (THOMPSON, 2012, p. 207-208).

A base do capitalismo é a propriedade privada dos meios de produção, cujo alicerce é o trabalho assalariado formalmente livre. Ele consiste na obtenção da mais-valia por meio do trabalhador, o qual é obrigado a alienar a sua força-trabalho a quem possui o capital, isto é, o proprietário. Nesta perspectiva, a sociedade foi erigida em parâmetros estritamente econômicos, calcados no lucro e na disciplina do tempo, uma vez que "as suas fundações, traves e vigas são todas feitas de material econômico. O edifício dá para o lado econômico da vida. Os prêmios e as penalidades são medidos em termos econômicos. Ascender ou retroceder significa fazer e perder dinheiro"3(SCHUMPETER, 2003, p. 73, destaque nosso).

A hipotética racionalização técnico-produtiva, científica e administrativa, manejada a partir da (des)regulamentação da "lógica do mercado", culmina na formação de um ethos particular e na organização de uma conduta de vida individual e coletiva. Para Anthony Giddens (1986, p. 317-318), “o capitalismo é uma sociedade de classes, e a contradição entre 'apropriação privada' e 'produção socializada' está encerrada em divisões de classes que, por sua vez, expressam interesses opostos" ". A cisão oscila em uma luta de ações e reações por meio de uma estrutura agudamente desigual que, por sua vez, não permite o desenvolvimento

\footnotetext{
${ }^{3}$ No original:"Its foundations, beams and beacons are all made of economic material. The building faces toward the economic side of life. Prizes and penalties are measured in pecuniary terms. Going up and going down means making and losing money".

${ }^{4}$ No original:"Capitalism is a class society and the contradiction between 'private appropriation' and 'socialized production' is locked into class divisions which in turn express opposing interests".
} 
de todas as potencialidades e liberdades. Se, explicitamente, há um horizonte de possibilidades, implicitamente, há uma exuberância de limites.

Esse antagonismo exacerbado constrói propositalmente um novo padrão cuja vulgata propaga a ideia de neutralidade do direito, como se sua fonte difusora fosse alheia ao complexo processo de (re)produção econômica. Conforme a síntese de Michel Miaille (1989, p. 68), "uma reflexão científica tem de ir mais longe e dizer-nos que tipo de direito produz tal tipo de sociedade e porque é que esse direito corresponde a essa sociedade”. As ideologias, principalmente as jurídicas, têm concebido, em cada época e em cada lugar, representações míticas que disseminam uma retórica normativa e camuflam a essência do sistema econômico predominante.

O acúmulo de capital, ou seja, o lucro, bem como a sua contrapartida, o risco, são consequências das condições heterogêneas inerentes à sociedade estratificada do "ter" e do "não ter". A Revolução Industrial e as revoluções tecnológicas subsequentes, fomentadas a partir do colonialismo ultramarino inglês, conduziram a transferência do processo de produção do artesanato e da manufatura para a fábrica, a qual possibilitou uma ampliação vertiginosa da produção e, por conseguinte, da concentração de pecúnia em benefício de pequenos grupos, formando-se os monopólios e os oligopólios. Após a industrialização, a "acumulação de capital e a expansão econômica adquiriram um impulso próprio"s (DOBB, 1962, p. 35-36).

As interpretações sobre os desdobramentos deste fenômeno são variadas. Desde a indústria de algodão, com as técnicas de fiação e tecelagem em grande escala, até a eletrônica e inteligência artificial (computação, robôs, energia nuclear), passando pelo uso do motor à combustão, o mundo passou por transformações em todos os níveis. Segundo Ulrich Beck (1997, p. 12), a deflagração da industrialização pode ser definida como modernização simples ou ortodoxa, ao passo que a evolução das tecnologias pode ser redefinida como modernização reflexiva: "Este novo estágio, em que o progresso pode se transformar em autodestruição, em que um tipo de modernização destrói outro e o modifica, é o que eu chamo de etapa da modernização reflexiva”. No bojo de mudanças radicais, a produção de riquezas se acentuou, quase sempre, concomitantemente à geração de riscos e à eclosão de catástrofes ambientais.Ressalte-se que

\footnotetext{
${ }^{5}$ No original:“[...]capital accumulation and economic expansion acquired a momentum of their own”.
} 
não é o modo de lidar com os riscos que diferencia a sociedade de risco da sociedade industrial, tampouco a melhor qualidade ou o maior alcance dos riscos produzidos por novas tecnologias e racionalizações. Decisivo é sobretudo o fato de que as circunstâncias sociais são radicalmente alteradas no curso de processos reflexivos de modernização: com a cientificização dos riscos da modernização, seu caráter latente é cancelado. O triunfo do sistema industrial faz com que as fronteiras entre a natureza e a sociedade se desvaneçam. Consequentemente, mesmo os danos à natureza já não poderão ser descarregados no "meio ambiente", convertendo-se, ao invés disto, com a universalização da indústria, em contradições sociais, políticas, econômicas e culturais imanentes ao sistema. Os riscos da modernização, tendo-se globalizado em termos sistêmicos e tendo perdido sua latência, não podem mais ser abordados conforme o modelo da sociedade industrial, assentado na suposição implícita da conformidade com as estruturas de desigualdade social; pelo contrário, eles desencadeiam uma dinâmica conflitiva, que se descola do esquematismo socioindustrial de produção e reprodução, classes, partidos e subsistemas(BECK, 2010, p. 232, destaque nosso).

De modo diverso ao que defende Ulrich Beck, não se trata de uma ruptura, mas de uma fratura, pois a sociedade industrial se metamorfoseou em uma sociedade industrial de riscos. No contexto da sociedade contemporânea, o avanço frenético da técnica associado a incertezas científicas acarreta a devastação do solo, acidentes tóxicos, poluição e a extinção de espécies, inclusive colocando em alerta a própria sobrevivência do ser humano. A degradação ambiental é tema compulsório da geopolítica mundial.

A tragédia anunciada decorre, outrossim, do fato de que o capitalismo parecer ser incapaz de assegurar o "desenvolvimento sustentável, não porque estimule os avanços tecnológicos capazes de forçar os recursos da terra, mas porque o propósito da produção capitalista é o valor de troca e não o valor de uso, o lucro e não as pessoas."6 (WOOD, 2002, p. 197). Os danos ambientais deixaram de ser compreendidos sob uma ótica meramente individual e material e passaram a ser mensurados à luz de uma dimensão coletiva e extrapatrimonial.

Por outro lado, Eugene F. Stoermer e Paul J. Crutzen denominaram esse novo período de "Antropoceno", em contraposição a "Holoceno", era de estabilidade ambiental durante o qual a humanidade cresceu e se desenvolveu. O trabalho foi publicado em 2000 no informativo Global Change Newsletter. Em 2004, Paul J. Crutzen, especialista em química atmosférica e Prêmio Nobel em 1995 pelos estudos sobre a camada de ozônio, juntamente com William C. Clark e Hans Joachim Schellnhuber, apresentaram um conceito: “"Antropoceno'- uma nova época geológica em que a humanidade surgiu como uma

\footnotetext{
${ }^{6}$ No original: "[...] sustainable development, not because it encourages technological advances that are capable of straining the earth's resources but because the purpose of capitalist production is exchange value not use value, profit not people."
} 
globalmente significativa - e potencialmente inteligente-força capaz de remodelar a face do planeta"7 (CLARK; CRUTZEN; SCHELLNHBER, 2004, p. 1). O mundo artificial passou a contracenar de forma mais contumaz e incisiva com o mundo natural. Consoante leciona Hans Jonas (2006, p. 43),

\begin{abstract}
hoje, na forma da moderna técnica, a techne transformou-se em um infinito impulso da espécie para adiante, seu empreendimento mais significativo. Somos tentados a crer que a vocação dos homens se encontra no contínuo progresso desse empreendimento, superando-se sempre a si mesmo, rumo a feitos cada vez maiores. A conquista de um domínio total sobre as coisas e sobre o próprio homem surgiria como a realização do seu destino. Assim, o triunfo do homo faber sobre o seu objeto externo significa, ao mesmo tempo, o seu triunfo na constituição interna do homo sapiens, do qual ele outrora costumava ser uma parte servil. Em outras palavras, mesmo desconsiderando suas obras objetivas, a tecnologia assume um significado ético por causa do lugar central que ela agora ocupa subjetivamente nos fins da vida humana. Sua criação cumulativa, isto é, o meio ambiente artificial em expansão, reforça, por um contínuo efeito retroativo, os poderes especiais por ela produzidos: aquilo que já foi feito exige o emprego inventivo incessante daqueles mesmos poderes para manter-se e desenvolver-se, recompensando-o com um sucesso ainda maior - o que contribui para o aumento de suas ambições. Esse feedback positivo de necessidade funcional e recompensa - em cuja dinâmica o orgulho pelo desempenho não deve ser esquecido - alimenta a superioridade crescente de um dos lados da natureza humana sobre todos os outros, e inevitavelmente às custas deles.
\end{abstract}

Para os cientistas que justificam o advento de um novo ciclo, a influência humana provocou alterações significativas na composição da própria natureza. Ao lançar gases tóxicos provenientes dos automóveis, chaminés e queimadas, a humanidade modificou a composição do carbono e, por via de consequência, elevou a temperatura, o derretimento de geleiras e o aumento do nível dos oceanos. Por sua vez, a indústria da construção civil transformou fisicamente o planeta com aço e concreto. Para Peter Sloterdijk (2018, p. 31), “el concepto de Antropoceno contiene los mínima moralia espontáneos de la era presente; implica la preocupación por la convivencia de los habitantes de la Tierra tanto en forma humana como no humana”. Além disso, a devastação prossegue com a poluição dos rios e mares com microplásticos, a dispersão de componentes radioativos oriundos de testes nucleares e a alteração dos índices de nitrogênio pelo uso de fertilizantes na agricultura.

Após a descrição das alterações na natureza provocadas, em grande medida, pela intervenção humana, principalmente após a Revolução Industrial, faz-se necessário abordar a questão do dano ambiental e do risco de retrocesso acaso seja acatada a tese da sua prescrição. Ressalte-se que a jurisprudência que concebeu a imprescritibilidade do dano ambiental funciona como ferramenta para a punição e proteção do meio ambiente.

\footnotetext{
${ }^{7}$ No original: "Anthropocene" - a new geologic epoch in which humankind has emerged as a globally significant - and potentially intelligent - force capable of reshaping the face of the planet".
} 


\section{O QUE É DANO AMBIENTAL?}

A Lei 6.938/81, a qual disciplina a Política Nacional do Meio Ambiente, não estabeleceu um conceito específico de dano ambiental. Há, contudo, uma definição de meio ambiente, degradação da qualidade ambiental e poluição ${ }^{8}$. A Declaração do Rio, aprovada na Conferência das Nações Unidas sobre o Meio ambiente e o Desenvolvimento (CNUMAD) em 1992, também não apresentou uma definição, restringindo-se a exortar os Estados à produção de normas concernentes à responsabilidade ${ }^{9}$. Antonio Herman de Vasconcelos e Benjamin(2011, p. 132) dissecou o texto legal com o seguinte epílogo:

Do texto da lei, bem se vê que o conceito normativo de meio ambiente é teleologicamente biocêntrico (permite, abriga e rege a vida em todas as suas formas), mas ontologicamente ecocêntrico (o conjunto de condições, leis, influências e interações de ordem física, química e biológica). Um grande avanço, sem dúvida, indo ao oposto da visão estritamente economicista (antropocêntrica) que caracterizou toda a história do direito nacional. Já a noção de poluição (a patologia) é um misto do pensamento antropocêntrico ("prejudiquem a saúde, a segurança e o bem-estar da população", "criem condições adversas às atividades sociais e econômicas", "afetem desfavoravelmente a biota") e ecocêntrico ("afetem as condições estéticas ou sanitárias do meio ambiente", "lancem matérias ou energia em desacordo com os padrões ambientais estabelecidos"). A partir das premissas legais podemos, genericamente, conceituar dano ambiental como a alteração, deterioração ou destruição, parcial ou total, de quaisquer dos recursos naturais, afetando adversamente o homem elou a natureza.

De acordo com a sua interpretação, o dano ambiental pode consistir em uma degeneração físico-química apenas da natureza, sem o comprometimento da espécie humana, o que reforça sobremaneira a ética ecocêntrica. Ney Maranhão (2018, p. 148) defende uma concepção ambiental que "vindique não apenas a firme preservação dos recursos naturais da Terra, em prol das gerações presentes e futuras mas, igualmente, sustente a promoção da vida

\footnotetext{
8 "Lei 6.938/81: Art. $3^{\circ}$ - Para os fins previstos nesta Lei, entende-se por: I - meio ambiente, o conjunto de condições, leis, influências e interações de ordem física, química e biológica, que permite, abriga e rege a vida em todas as suas formas; II - degradação da qualidade ambiental, a alteração adversa das características do meio ambiente; III - poluição, a degradação da qualidade ambiental resultante de atividades que direta ou indiretamente:a) prejudiquem a saúde, a segurança e o bem-estar da população;

b) criem condições adversas às atividades sociais e econômicas; c) afetem desfavoravelmente a biota; d) afetem as condições estéticas ou sanitárias do meio ambiente;e) lancem matérias ou energia em desacordo com os padrões ambientais estabelecidos". BRASIL, 1981, on-line.

9 "Princípio 13. Os Estados irão desenvolver legislação nacional relativa à responsabilidade e à indenização das vítimas de poluição e de outros danos ambientais. Os Estados irão também cooperar, de maneira expedita e mais determinada, no desenvolvimento do direito internacional no que se refere à responsabilidade e à indenização por efeitos adversos dos danos ambientais causados, em áreas fora de sua jurisdição, por atividades dentro de sua jurisdição ou sob seu controle". DECLARAÇÃO DO RIO DE JANEIRO, 1992, p. 156.
} 
e da saúde humana". Trata-se, como é perceptível, de visão estritamente antropocêntrica, a qual põe a natureza em uma condição passiva sempre tendo que se adaptar ao mito das necessidades humanas ilimitadas. Mesmo quando enaltece a preservação ambiental, a vincula a gerações futuras de seres humanos, em descompasso com a visão holística que reclama o meio ambiente.

Em refutação, KlausBosselmann (2017, p. 104)ensina que “a sustentabilidade ecológica refere-se aos valores intrínsecos de "outros não humanos" que podem ser expresso em conceitos jurídicos, em especial, na ideia de justiça". No plano do direito internacional, Leonardo Estrela Borges (2017, p. 357-358), ao passo em que endossa uma perspectiva ecocêntrica, também sublinha a carência de uma definição de dano ambiental:

\begin{abstract}
Admitir o valor intrínseco dos elementos naturais equivale a admitir igualmente a possibilidade de um dano que não possui repercussões relacionadas a um interesse humano particular, mas que afeta um interesse coletivo legítimo, dado que não somente os componentes materiais do meio ambiente são levados em consideração, mas também os processos ecológicos de interação entre estes componentes e as funções executadas em benefício de um recurso natural. [...]. No entanto, mesmo quando um tratado reconhece o valor do meio ambiente ou o define de modo a englobar componentes materiais e imateriais da natureza, ele não afirma expressamente a existência do dano ao meio ambiente per se, o que ainda deixa dúvidas sobre o seu reconhecimento jurídico. O exemplo da Convenção de Lugano sobre a Responsabilidade Civil pelos Danos Resultantes de Atividades Perigosas para o Meio Ambiente é esclarecedor, chegando certos autores até mesmo a afirmar que ela admite a possibilidade do dano ecológico puro. Contudo, se ela define meio ambiente segundo uma abordagem sistêmica e inclui no conceito de dano "qualquer perda ou dano resultante de alteração do meio ambiente", ela limita a reparação "ao custo das medidas de recuperação que foram efetivamente adotadas ou que o serão". Desse modo, a Convenção não faz nada mais do que seguir os diversos tratados de responsabilidade civil dos operadores de uma atividade perigosa, ao adotar uma visão tradicional do dano ecológico.
\end{abstract}

O dano ambiental pode ser compreendido como toda modificação negativa no meio ambiente em sentido amplo, "classificado tanto como macrobem de interesse da coletividade, em uma concepção totalizante e, indiretamente, a terceiros, tendo em vista interesses próprios e individualizáveis e que refletem no microbem"(LEITE; CAETANO, 2013, p. 284). Estas categorias são extremamente relevantes porque reforçam a complexidade e a opulência do meio ambiente. $\mathrm{O}$ macrobem é um sistema que permite rever a vida em todas as suas formas e dimensões, o meio ambiente como unidade global. O microbem é formado por subsistemas, os quais mantêm relações internas entre si e relações externas com o macrobem, a exemplo da flora, da fauna, do solo e da água. Após a descrição do conceito de bem ambiental faz-se necessário abordar a questão da evolução da proteção do meio ambiente no Brasil. Trata-se de 
aspecto importante do problema porque a tese da prescrição do dano ambiental acarretará, acaso acatada, em um dos maiores retrocessos na proteção do meio ambiente.

\section{EVOLUÇÃO DA PROTEÇÃO DO MEIO AMBIENTE NO BRASIL}

Com a colonização portuguesa no início do século XVI, o território sob domínio ibérico passou a ser disciplinado pelas Ordenações do Reino, primeiramente as Manuelinas, até 1548 , e, a partir de 1603, pelas Filipinas, além de outros atos normativos, como Cartas de Doação, Forais, Cartas Régias, Alvarás e Regimentos dos Governadores Gerais. Juraci Perez Magalhães destaca que, em caráter de vanguarda na tutela do meio ambiente, as Ordenações Manuelinas, "no Livro V, título LXXXIII proibia a caça de perdizes, lebres e coelhos e, no título 'C', tipificava o corte de árvores frutíferas como crime" (MAGALHÃES,1998, p. 2627). Em 1605, destinado à proteção das florestas, foi publicado o Regimento do Pau-Brasil.

No que tange às águas, em 1797, a Carta régia afirmou a necessidade de proteção a rios, nascentes e encostas, os quais passaram a ser reconhecidos formalmente como propriedades da Coroa. Sob o jugo imperial, em 1850, houve a publicação da Lei ${ }^{\circ}$ 601, considerada a primeira "Lei de Terras" do Brasil. Ela disciplinou a ocupação do solo e estabeleceu sanções para atividades predatórias. Na fase da República, o Decreto $\mathrm{n}^{\circ} 8.843$, de 1911, criou a primeira reserva florestal do Brasil, no antigo Território do Acre. O Código Civil Brasileiro de 1916, cujo esboço deve-se a Augusto Teixeira de Freitas, a maior autoridade em direito romano de sua geração, refletiu a visão patrimonial, de cunho individualista, própria da época, egressa de um dos regimes mais longos de escravidão.

Em 1934 foram sancionados o Código Florestal, que impôs limites ao exercício do direito de propriedade, e o Código de Águas. Sob a égide do regime militar, em 1964 houve o advento da Lei 4.504, conhecida como "Estatuto da Terra", cuja origem decorre de reivindicações de movimentos sociais que exigiam mudanças estruturais na propriedade e no uso da terra no Brasil, país detentor de grandes concentrações de latifúndio.

No ano seguinte passou a vigorar uma nova versão do Código Florestal, a qual ampliou políticas de proteção e conservação da flora. Inovador, estabeleceu a proteção das áreas de preservação permanente. Em 1967 foram editados os Códigos de Caça, de Pesca e de Mineração, bem como a Lei de Proteção da Fauna. Por meio do Decreto-Lei 1.413, de 1975, 
empresas poluidoras ficam obrigadas a prevenir e corrigir os prejuízos da contaminação do meio ambiente. É o início do controle da poluição provocada por atividades industriais.

Em 1977 foi publicada a Lei 6.453, que estabeleceu a responsabilidade civil em casos de danos provenientes de atividades nucleares. Tais instrumentos são resultado da Conferência de Estocolmo, de 1972, a primeira grande reunião de chefes de Estado organizada pelas Nações Unidas (ONU) para tratar das questões relacionadas à degradação do meio ambiente.Neste particular, Natália Paulino Bonnoni (2019, p. 47) informa que

\begin{abstract}
as Conferências internacionais promovidas pela ONU foram essenciais à efetivação da tutela internacional do meio ambiente. A Conferência de Estocolmo, que aconteceu em 1972, lançou as bases para a proteção internacional do meio ambiente. Já a Conferência do Rio de Janeiro, que ocorreu em 1992, consolidou a visão do desenvolvimento sustentável, que promove o crescimento econômico sem comprometer os recursos para as presentes e futuras gerações. Foram realizadas, ainda, as Conferências de Joanesburgo e novamente do Rio de Janeiro, em 2002 e 2012, respectivamente, as quais não resultaram em mudanças significativas para a tutela internacional do meio ambiente.
\end{abstract}

Em 1981, a Lei 6.938, a qual estabeleceu a Política Nacional de Meio Ambiente, inovou ao apresentar o meio ambiente como objeto específico de proteção. Para robustecer o leque de salvaguarda, a Lei 7.347/85 disciplinou a ação civil pública como instrumento processual específico para a defesa do meio ambiente e de outros interesses difusos e coletivos. A Constituição Federal de 1988, a primeira a dedicar capítulo específico ao meio ambiente, impõe ao Poder Público e à coletividade o dever de defender e preservar o meio ambiente para as gerações presentes e futuras.

Na última década do século XX, duas leis se sobressaem no panorama ambiental. Em primeiro lugar, a Lei 8.171/91 dispõe, em caráter geral, sobre a Lei de Política Agrícola e, em caráter particular, obriga o proprietário rural a recompor sua propriedade com reserva florestal obrigatória. Em segundo lugar, foi publicada a Lei 9.605/98, que dispõe sobre crimes ambientais. Em 2000, por intermédio da Lei 9.985/00, foi criado o Sistema Nacional de Unidades de Conservação, o qual prevê mecanismos para a defesa dos ecossistemas naturais e de preservação dos recursos naturais neles contidos.

$\mathrm{Na}$ sequência, o "Estatuto das Cidades" (Lei 10.257/2001) fornece aos entes municipais mecanismos visando permitir que seu desenvolvimento não ocorra em detrimento do meio ambiente. A Lei Complementar 140/2011 fixou normas de cooperação entre os entes federados no exercício da competência comum. A polêmica Lei 12.651/2012, que dispõe sobre a proteção da vegetação nativa, ficou conhecida como sendo o novo Código 
Florestal.Em relação ao Código Florestal, foram ajuizadas uma ação direta de constitucionalidade (ADC) e quatro ações diretas de inconstitucionalidade (ADI's). Em suma, o Supremo Tribunal Federal (STF) endossou a visão antropocêntrica inserta no artigo 225 da Constituição Federal sob os seguintes argumentos: i) a proteção ambiental deve conviver com a tutela do desenvolvimento; ii) a proteção ambiental não significa ausência completa de impacto do homem na natureza; e iii) o princípio da vedação ao retrocesso não está acima do princípio democrático (BRASIL. STF, ADC 42/DF e ADI's 4.901/DF, 4.902/DF, 4.903/DF e 4.937/DF, 2018).

\section{QUESTÕES MATERIAIS E PROCESSUAIS DA DISCIPLINA JURÍDICA DO DANO AMBIENTAL}

O direito ambiental é um ramo relativamente novo do sistema jurídico. Além da Constituição Federal ter pouco mais de três décadas de vigência, a sua disciplina foi construída, em grande medida, pela jurisprudência dos Tribunais Superiores, principalmente do Superior Tribunal de Justiça. Neste sentido, perante as inúmeras lacunas existentes no microssistema ambiental, é importante a explanação a respeito das peculiaridades materiais e formais do direito e do dano ambiental concebidas pelas decisões judiciais, como a natureza da responsabilidade civil e o devido processo ambiental.

\subsection{NATUREZA DA RESPONSABILIDADE CIVIL POR DANO AMBIENTAL: A TEORIA DO RISCO INTEGRAL E A SOLIDARIEDADE}

O direito ambiental evoluiu bastante após a promulgação da Constituição Federal de 1988. Além do esforço do Poder Legislativo, registre-se o papel central exercido pelo Superior Tribunal de Justiça, doravante STJ. Em sede de responsabilidade civil, todos os poluidores são solidariamente responsáveis pelos danos ambientais. Neste sentido, mesmo havendo "múltiplos agentes poluidores, não existe obrigatoriedade na formação do litisconsórcio, abrindo-se ao autor a possibilidade de demandar de qualquer um deles, isoladamente ou em conjunto, pelo todo" (BRASIL. STJ, Recurso Especial 880.160/RJ, 2010, on-line). 
Em que pese a regra da solidariedade, há uma tendência de importação da doutrina norte-americana do "bolso profundo" (deep pocket), segundo a qual a prioridade na responsabilização deve incidir na pessoa que arregimenta mais condições de arcar com os prejuízos. Mesmo nesta hipótese, "não há falar em caráter de punição à luz do ordenamento jurídico brasileiro - que não consagra o instituto de direito comparado dos danos punitivos" (BRASIL. STJ, Recurso Especial 1.354.536/SE, 2014, on-line). A inadmissibilidade do punitive damages advém de duas peculiaridades do nosso sistema: i) a responsabilidade civil por dano ambiental prescinde de culpa; e ii) a função punitiva deve ser reservada ao direito penal e ao direito administrativo.

Com efeito, o STJ entende que a responsabilidade civil ambiental é objetiva e mediante a teoria do risco integral, consoante previsão do artigo $14, \S 1^{\circ}$, da Lei 6.938/81 ${ }^{10} \mathrm{e}$ do artigo 225, $\S 3^{\circ}$, da Constituição Federal. O poluidor é obrigado a indenizar ou reparar os danos, sendo irrelevante o elemento subjetivo, ou seja, se a ação ou a omissão se desenvolveu mediante dolo ou culpa.

Por se tratar de responsabilidade civil baseada no risco integral, o direito ambiental brasileiro não admite as excludentes do fato de terceiro, de culpa concorrente da vítima, pois a titularidade é a coletividade, e do caso fortuito ou força maior. Observe-se que o pressuposto para a aplicação da teoria do risco integral é a existência de atividades que acarretem riscos para a saúde e para o meio ambiente. Quem explora atividade econômica se coloca na posição de garantidor, assumindo o dever de prevenção dos riscos. Trata-se, pois, da aplicação cumulativa do princípio da prevenção e do poluidor-pagador.

No tocante à responsabilidade civil do Estado por dano ambiental, pode-se afirmar a sua natureza solidária, ilimitada e objetiva (BRASIL. STJ, Recurso Especial 604.725/PR, 2005, on-line), mesmo na hipótese de omissão na fiscalização do meio ambiente (BRASIL. STJ, Recurso Especial 1.071.741/SP, 2010), sendo regida pelos princípios do ressarcimento integral, da prioridade da reparação in natura, entre outros.Entretanto, em relação à solidariedade, a responsabilidade é de execução subsidiária, sob pena de o ente público se transfigurar em segurador universal. Acentue-se que a responsabilidade emerge somente quando o dever de fiscalizar for determinante para a concretização ou agravamento do dano

\footnotetext{
10 "Lei 6.938/81, artigo 14, § $1^{\circ}$ Sem obstar a aplicação das penalidades previstas neste artigo, é o poluidor obrigado, independentemente da existência de culpa, a indenizar ou reparar os danos causados ao meio ambiente e a terceiros, afetados por sua atividade. O Ministério Público da União e dos Estados terá legitimidade para propor ação de responsabilidade civil e criminal, por danos causados ao meio ambiente". BRASIL, 1981.
} 
provocado pelo causador direto (BRASIL. STJ, Agravo Regimental no Recurso Especial 1.001.780/PR, 2011, on-line).

\subsection{DEVIDO PROCESSO AMBIENTAL: DENUNCIAÇÃO DA LIDE, INVERSÃO DO ÔNUS DA PROVA, DESCONSIDERAÇÃO DA PERSONALIDADE JURÍDICA E NEXO DE CAUSALIDADE}

A discussão entre os possíveis responsáveis pelo dano ambiental é matéria privada e não pode procrastinar a reparação e o pagamento das respectivas indenizações. Sob o ângulo dos princípios da economia e celeridade processuais, é inadmissível a denunciação da lide, uma vez que a responsabilidade pelo dano ambiental é objetiva e a responsabilidade existente entre os pretensos denunciante e denunciado é do tipo subjetiva (BRASIL. STJ, Agravo Regimental no Agravo 1.213.458/MG, 2010, on-line).

Em relação ao ônus da prova, o STJ passou a admitir a sua inversão nas ações de reparação dos danos ambientais com base no interesse público da reparação e no princípio da precaução. A propósito, trata-se de técnica de julgamento na hipótese de dúvida probatória (non liquet), pois impõe ao suposto poluidor o ônus de comprovar que inexiste dano ambiental a ser reparado ou, porventura existente, que este não foi de sua autoria (BRASIL. STJ, Recurso Especial 972.902/RS, 2009, on-line). Ademais, superada a viabilidade da inversão do ônus da prova, decidiu-se que "a inversão ope judicis do ônus da prova deve ocorrer preferencialmente no despacho saneador" (BRASIL. STJ, Recurso Especial 802.832/MG, 2011, on-line) e não mais na sentença.

$\mathrm{Na}$ esfera ambiental, bem como no âmbito do direito do consumidor e da Lei 12.529/2011 (Lei Antitruste), adota-se a teoria menor da desconsideração da personalidade jurídica. A teoria maior da desconsideração, em regra, no sistema jurídico brasileiro, não pode ser aplicada com a mera demonstração de estar a pessoa jurídica insolvente para o cumprimento de suas obrigações. Exige-se, aqui, para além da prova de insolvência, ou a demonstração de desvio de finalidade (teoria subjetiva da desconsideração), ou a demonstração de confusão patrimonial (teoria objetiva da desconsideração). A teoria menor da desconsideração, por outro lado, incide com a mera prova de insolvência da pessoa jurídica para o pagamento de suas obrigações, independentemente da existência de desvio de 
finalidade ou de confusão patrimonial (BRASIL. STJ, Recurso Especial 279.273/SP, 2004, on-line).

No que pertinente ao nexo de causalidade, este consiste no vínculo, ou seja, no fator aglutinador que une conduta, comissiva ou omissiva, e o resultado, efetivo ou potencial, variando a sua consecução consoante a teoria adotada. Em regra, o nexo de causalidade funciona como um pressuposto imprescindível para a configuração da responsabilidade civil, mesmo na hipótese de responsabilidade civil objetiva pela teoria do risco integral.

Embora não se amolde perfeitamente ao direito ambiental, em virtude da complexidade de causas e concausas, a teoria da equivalência das condições é a que possui mais afinidade com a responsabilidade civil por danos ambientais, sobretudo porque engloba o poluidor indireto. Por outro lado, em relação ao poluidor direto, pode-se analisar a sua conduta sob o prisma da teoria dos danos direitos e imediatos. Além disso, em caráter excepcional, haverá dispensa do nexo causal quando se tratar de obrigação ambulatória ou propter rem, em face de sua natureza real e não pessoal (BRASIL. STJ, Recurso Especial 650.728/SC, 2009, on-line).

\subsection{A TESE DA (IM)PRESCRETIBILIDADE E A REPERCUSSÃO GERAL NO RECURSO EXTRAORDINÁRIO 654.833/AC.}

Na dicção do STJ,não há nenhuma celeuma quanto à natureza imprescritível da pretensão reparatória por danos ao meio ambiente. Com efeito, "é imprescritível o direito de ação coletiva em se tratando de pretensão que visa à recuperação de ambiente degradado, pois o dano apontado tem a característica de violação continuada" (BRASIL. STJ, Recurso Especial 647.493/SC, 2007, on-line). Portanto, é perpétua, se protrai no tempo. De modo diverso, o dano pessoal, de caráter exclusivamente individual e decorrente de acidente ambiental, está sujeito à prescrição quinquenal (BRASIL. STJ, Recurso Especial 1.437.847, 2015, on-line).

O Supremo Tribunal Federal, em 31 de maio de 2018, reconheceu a Repercussão Geral do Recurso Extraordinário 654.833, que trata de dano causado por madeireiros na exploração de terras indígenas no Acre nos anos 1980, e no qual se busca afastar a tese da imprescritibilidade. Questiona-se acórdão do Superior Tribunal de Justiçaque reconheceu a imprescritibilidade do dano ambiental, sob o argumento de ser inconstitucional a interpretação 
conferida por aquele tribunal ao artigo 37 , parágrafo $5^{\circ}$, da Constituição Federal, segundo o qual "a lei deve prever prazos de prescrição para ilícitos que causem prejuízos ao erário, ressalvadas as ações de ressarcimento", e também ao artigo 225 , parágrafo $3^{\circ}$, que trata do dano ambiental. As alegações do recurso são de que os fatos são anteriores à promulgação da Constituição Federal de 1988, devendo ser desconsiderada a lógica da imprescritibilidade e observado o prazo prescricional de cinco anos previsto na Lei da Ação Popular (Lei 4.717/1965). Em sua manifestação no Plenário Virtual do STF, o relator, ministro Alexandre de Moraes (BRASIL. STF, Recurso Extraordinário 654.833 RG/AC, 2018,on-line), entendeu que a matéria da imprescritibilidade, tratada pela decisão do STJ, merece ser apreciada pelo Supremo:

\begin{abstract}
A repercussão geral inserta na controvérsia é indiscutível, seja sob o ângulo jurídico, econômico ou social, devido ao seu impacto na seara das relações jurídicas as quais têm por pano de fundo a pretensão à reparação civil cuja causa de pedir derive de danos causados ao meio ambiente", afirmou. Também observou que a temática do alcance da prescritibilidade das ações de ressarcimento tem sido objeto de recorrentes considerações do Supremo. Isso demonstra, segundo Moraes, a relevância de se 'estabelecer balizas precisas e seguras sobre a incidência do instituto da prescrição nos peculiares casos envolvendo direitos individuais ou coletivos lesados, direta ou indiretamente, em razão de danos ambientais'.
\end{abstract}

No caso concreto, a primeira instância da Justiça Federal, ao julgar ação civil pública ajuizada pelo Ministério Público Federal, fixou indenização de aproximadamente R $\$ 1,5$ milhão por danos materiais decorrentes dos prejuízos causados com a extração ilegal de madeira, R\$ 3 milhões por danos morais em favor da comunidade indígena AshaninkaKampa, e mais R $\$ 6$ milhões para custear a recomposição ambiental, a serem repassados ao Fundo de Defesa de Direitos Difusos. A expectativa do julgamento traduz atualmente o debate central no âmbito das universidades, cientistas e organizações de proteção do meio ambiente, principalmente após a interpretação conferida ao Código Florestal por parte do Supremo Tribunal Federal.

\title{
6 CONCLUSÃO
}

A ideia do desenvolvimento sustentável, ícone do Relatório Brundtland, de 1987, reafirmado na Declaração do Rio de Janeiro, de 1992, representa um modelo de desenvolvimento no qual se almeja um equilíbrio entre os recursos naturais e a sociedade de consumo em massa, a fim de que não se comprometa a capacidade de atender as necessidades 
das futuras gerações. Entretanto, no campo do direito ambiental, os acordos são mais protocolos de intenções do que tratados bilaterais ou multilaterais propriamente ditos. A título de ilustração, no Acordo de Paris de 2015, sobre mudança climática, os Estados Unidos anunciaram a sua retirada, pois, segundo eles, a China goza de condições mais favoráveis. Ocorre que China e Estados Unidos respondem por cerca de $40 \%$ de todas as emissões de gases poluentes na atmosfera.

A característica de um modo de produção capitalista difusor de desigualdades sociais tão antagônicas repercute diretamente na questão ambiental. Os países economicamente mais desenvolvidos atualmente contam com aproximadamente um quinto da população do mundo, mas são responsáveis por mais de $75 \%$ das emissões que poluem a atmosfera e aceleram o aquecimento global. A pobreza é um dos fatores que contribuem para práticas que levam à degradação ambiental em países subdesenvolvidos, e pessoas que vivem em situação de escassez não têm opção além de fazer o uso máximo dos recursos locais que lhe são disponíveis. A principal causa da degeneração do meio ambiente consiste na intervenção técnica do homem aliada à obtenção, a qualquer custo, do lucro.

Neste sentido, os reflexos de novas tecnologias e de perpetuação das contradições entre classes parecem se agravar nos países de subdesenvolvimento econômico. No Brasil, em especial, há um processo de relativização dos problemas que envolvem o meio ambiente. $\mathrm{O}$ reconhecimento da constitucionalidade de normas polêmicas do Código Florestal e da repercussão geral no Recurso Extraordinário 654.833/AC despertam uma preocupação com conquistas e direitos consagrados na Constituição Federal e reforçam a tese de um retrocesso jurisprudencial. Os percalços à preservação ambiental somente serão removidos com o uso de tecnologias ecoeficientes, com um sistema econômico socialmente mais justo e, principalmente, com uma educação capaz de integrar, em total harmonia, a comunidade e a natureza.

\section{REFERÊNCIAS}

BECK, Ulrich. A reinvenção da política: rumo a uma teoria da modernização reflexiva. In: BECK, Ulrich; GIDDENS, Anthony; LASH, Scott. Modernização reflexiva: política, tradição e estética na ordem social moderna. Tradução de Magda Lopes. São Paulo: Unesp, 1997. p. 11-71. 
Sociedade de risco: rumo a uma outra modernidade. Tradução de Sebastião Nascimento. São Paulo: Editora 34, 2010.

BENJAMIN, Antonio Herman de Vasconcellos e. Responsabilidade civil pelo dano ambiental. In: MILARÉ, Édis; MACHADO, Paulo Affonso Leme (orgs.). Direito ambiental: responsabilidade em matéria ambiental. São Paulo: Editora Revista dos Tribunais, 2011. p. 75-136.

BONNOMI, Natália Paulino. Tutela ambiental e seus reflexos no Direito Internacional. Revista de Direito Ambiental, São Paulo, v. 93, a. 24, p. 29-49, jan./mar. 2019.

BORGES, Leonardo Estrela. As obrigações de prevenção no direito ambiental internacional. São Paulo: Saraiva, 2017.

BOSSELMANN, Klaus. The principle of sustainability: transforming law and governance. 2. ed. New York: Routledge, 2017.

BRASIL. Lei 6.938, de 31 de agosto de 1981. Dispõe sobre a Política Nacional do Meio Ambiente, seus fins e mecanismos de formulação e aplicação, e dá outras providências. Presidência da República, Brasília, 1981. Disponível em: http://www.planalto.gov.br/. Acesso em: 19 jun. 2019.

BRASIL. Superior Tribunal de Justiça. Agravo Regimental no Agravo 1.213.458/MG. Rel. Min. Mauro Campbell Marques. Diário da Justiça, Brasília, 30 set. 2010.

BRASIL. Superior Tribunal de Justiça. Agravo Regimental no Recurso Especial 1.001.780/PR. Rel. Min. Teori Albino Zavascki. Diário da Justiça, Brasília, 04 out. 2011.

BRASIL. Superior Tribunal de Justiça. Recurso Especial 279.273/SP. Rel. Min. Ari Pargendler. Rel. p/ Acórdão Min. Nancy Andrighi. Diário da Justiça, Brasília, 29 mar. 2004.

BRASIL. Superior Tribunal de Justiça. Recurso Especial 604.725/PR. Rel. Min. Castro Meira. Diário da Justiça, Brasília, 22 ago. 2005.

BRASIL. Superior Tribunal de Justiça. Recurso Especial 647.493-SC. Rel. Min. João Otávio de Noronha. Diário da Justiça, Brasília, 15 maio 2007.

BRASIL. Superior Tribunal de Justiça. Recurso Especial 650.728/SC. Rel. Min. Herman Benjamin. Diário da Justiça, Brasília, 02 dez. 2009.

BRASIL. Superior Tribunal de Justiça. Recurso Especial 802.832-MG. Rel. Min. Paulo de Tarso Sanseverino. Diário da Justiça, Brasília, 13 nov. 2011.

BRASIL. Superior Tribunal de Justiça. Recurso Especial 880.160/RJ. Rel. Ministro Mauro Campbell Marques. Diário da Justiça, Brasília, 27 maio 2010.

BRASIL. Superior Tribunal de Justiça. Recurso Especial 972.902-RS. Rel. Min. Eliana Calmon. Diário da Justiça, Brasília, 25 ago. 2009. 
BRASIL. Superior Tribunal de Justiça. Recurso Especial 1.071.741/SP. Rel. Min. Herman Benjamin. Diário da Justiça, Brasília, 16 dez. 2010.

BRASIL. Superior Tribunal de Justiça. Recurso Especial 1.354.536-SE. Rel. Min. Luis Felipe Salomão. Diário da Justiça, Brasília, 26 mar. 2014.

BRASIL. Superior Tribunal de Justiça. Recurso Especial 1.437.847. Rel. Min. João Otávio de Noronha. Diário da Justiça, Brasília, 26 ago. 2015.

BRASIL. Supremo Tribunal Federal. ADC 42/DF, ADI 4.901/DF, ADI 4.902/DF, ADI 4.903/DF e ADI 4.937/DF. Rel. Min. Luiz Fux. Diário de Justiça, Brasília, 8 mar. 2018.

BRASIL. Supremo Tribunal Federal. Recurso Extraordinário 654.833 RG/AC. Rel. Min. Alexandre de Moraes. Diário da Justiça, Brasília, 31 maio 2018.

CLARK, William. C.; CRUTZEN, Paul Josef; SCHELLNHUBER, Hans Joachim. Science for global sustainability: toward a new paradigm. In: SCHELLNHUBER, Hans Joachim et al. (Edited by). Earth system analysis for sustainability. Cambridge, Massachusetts, London, U.K.: The MIT Press; Dahlem University Press, 2004. p. 1-28.

CONSTITUCIÓN DE LA REPÚBLICA DEL ECUADOR. Brasília, Supremo Tribunal Federal,2008.Disponívelem:http://www.stf.jus.br/repositorio/cms/portalStfInternacional/news letterPortalInternacionalFoco/anexo/ConstituicaodoEquador.pdf. Acesso em: 19 jun. 2019.

CONSTITUIÇÕES DO BRASIL. In: CAMPANHOLE, Hilton Lobo; CAMPANHOLE, Adriano (orgs.). 14. ed. São Paulo: Atlas, 2000. p. 5-227.

DECLARAÇÃO do Rio de Janeiro. Estudos Avançados, v. 6, n. 15, p. 153-159, 1992. Disponível em: http://www.scielo.br/pdf/ea/v6n15/v6n15a13.pdf. Acesso em: 19 jun. 2019.

DOBB, Maurice. Capitalism yesterday and today. New York: Monthly Review Press, 1962.

FRANZOLIN, Cláudio José; CASTRO, Isabella Silveira de. Obrigação propter rem e direito ambiental: análise à luz de casos decididos no Superior Tribunal de Justiça. Revista de Direito Ambiental, São Paulo, v. 93, a. 24, p. 89-127, jan./mar. 2019.

GIDDENS, Anthony. The constitution of society. Cambridge, UK: Polity Press, 1986.

JONAS, Hans. O princípio responsabilidade: ensaio de uma ética para a civilização tecnológica. Tradução de Marijane Lisboa e Luiz Barros Montez. Rio de Janeiro: Contraponto; Ed. PUC-Rio, 2006.

LEITE, José Rubens Morato; CAETANO, Matheus Almeida. A responsabilidade civil por danos ambientais na sociedade de risco: um direito reflexivo frente às gerações de problemas ambientais. In: LOPEZ, Teresa Ancona; LEMOS, Patrícia Faga Iglecias; RODRIGUES JÚNIOR, Otávio Luiz (coords.). Sociedade de risco e direito privado: desafios normativos, consumeristas e ambientais. São Paulo: Atlas, 2013. p. 273-295. 
MAGALHÃES, Juraci Perez. A evolução da legislação ambiental no Brasil. São Paulo: Editora Oliveira Mendes, 1998.

MARANHÃO, Ney. Meio ambiente: descrição jurídico-conceitual. Revista de Direito Ambiental, São Paulo, v. 90, a. 23, p. 117-151, abr./jun. 2018.

MIAILLE, Michel. Introdução crítica ao direito. 2. ed. Lisboa: Editorial Estampa, 1989.

SCHUMPETER, Joseph A. Capitalism, socialism and democracy. London, New York: Routledge, 2003.

SLOTERDIJK. Peter. ¿Que sucedió em elsiglo XX? Traducción del alemán de Isidoro Reguera. Madrid: Siruela, 2018.

THOMPSON, Edward Palmer. Modos de dominação e Revolução na Inglaterra. In: NEGRO, Antonio Luigi; SILVA, Sergio (orgs.). As peculiaridades dos ingleses e outros artigos/Edward Palmer Thompson. Tradução de Fernando Teixeira da Silva. 2. ed. Campinas, SP: Editora da Unicamp, 2012. p. 203-225.

WOOD, Ellen Meiksins. The origin of capitalism: a longer view. London, New York: Verso, 2002. 